\title{
Association of the MSX2 gene polymorphisms with ankylosing spondylitis in Japanese
}

\author{
Tatsuya Furuichi · Koichi Maeda $\cdot$ Chung-Tei Chou $\cdot$ Yu-Fen Liu $\cdot$ Ting-Chun Liu • \\ Yoshinari Miyamoto · Atsushi Takahashi · Kanji Mori · Katsunori Ikari · Naoyuki Kamatani · \\ Hisashi Kurosawa $\cdot$ Hisashi Inoue $\cdot$ Shih-Feng Tsai $\cdot$ Shiro Ikegawa
}

Received: 18 December 2007 / Accepted: 29 January 2008/Published online: 26 February 2008

(C) The Japan Society of Human Genetics and Springer 2008

\begin{abstract}
Several genes have been implicated in the etiology of ankylosing spondylitis (AS); however, the significance of these genes except HLA-B27 remains to be elucidated. In this study, we examined the association of AS with novel candidate genes and previously reported genes other than HLA-B27. We examined a total of 45
\end{abstract}

Tatsuya Furuich and Koichi Maeda contributed equally to this work.

T. Furuichi $\cdot$ K. Maeda $\cdot$ Y. Miyamoto $\cdot$ S. Ikegawa $(\bowtie)$ Laboratory for Bone and Joint Diseases, SNP Research Center, RIKEN, 4-6-1 Shirokanedai, Minato-ku, Tokyo 108-8639, Japan e-mail: sikegawa@ims.u-tokyo.ac.jp

K. Maeda $\cdot$ H. Kurosawa $\cdot$ H. Inoue

Department of Orthopaedics Surgery, Juntendo University

School of Medicine, Tokyo, Japan

C.-T. Chou

Division of Allergy-Immunology-Rheumatology,

Department of Medicine, Taipei Veterans General Hospital,

Taipei, Taiwan

Y.-F. Liu · T.-C. Liu · S.-F. Tsai

Genome Research Center, National Yang-Ming University,

Taipei, Taiwan

\section{A. Takahashi $\cdot$ N. Kamatani}

Laboratory for Statistical Analysis, SNP Research Center, RIKEN, Tokyo, Japan

\section{K. Mori}

Department of Orthopaedic Surgery, Shiga University

of Medical Science, Otsu, Japan

K. Ikari · N. Kamatani

Institute of Rheumatology, Tokyo Woman's Medical

University, Tokyo, Japan

S.-F. Tsai

Division of Molecular and Genomic Medicine, National Health

Research Institutes, Zhunan, Miaoli, Taiwan single nucleotide polymorphisms (SNPs) in 15 genes by a sequential screening. We first genotyped 170 Japanese AS patients and 896 controls for the SNPs (first screen). Then, we genotyped eight SNPs with $P<0.05$ in the first screen for 108 additional Japanese patients (second screen). We checked the replication of the association of the most significant SNP by genotyping 219 Taiwanese AS patients and 185 controls. When the first and second screens were combined, four SNPs showed nominal significance of $P<0.05$. An intronic SNP (IVS1 $+996 \mathrm{G}>\mathrm{A}$ ) in $M S X 2$, a novel candidate gene, showed the most significant association $(P=0.0030)$. The association was not replicated in our Taiwanese population; however, there was the same trend with the Japanese population in the allelic frequency distribution of the SNP. In the genes previously reported to have association with AS, only one synonymous SNP, c.963T $>\mathrm{G}$ in $A N K H$, showed a marginal association in the Japanese population $(P=0.045)$.

Keywords Ankylosing spondylitis · Association · Single-nucleotide polymorphism markers $\cdot$ MSX2 $\cdot$ ANKH

\section{Introduction}

Ankylosing spondylitis (AS) [MIM 106300] is one of the common causes of inflammatory arthropathy, with a prevalence of $0.1-0.8 \%$ in Caucasians (Calin 1998). AS affects predominantly the axial skeleton and spinal and sacroiliac joints and eventually causes their bony ankylosis. AS frequently involves the peripheral joints and entheses and occasionally extra-articular sites such as uvea, aorta, heart, lung, and kidney.

Strong genetic factors have been implicated in the etiology of AS. A sibling risk ratio $(\lambda s)$ is estimated to be $82 \%$ 
(Brown et al. 2002), and a heritability assessed by twin studies $>90 \%$ (Brown et al. 1997). HLA-B27 is the strongest genetic factor known for AS (Brewerton et al. 1973). More than $90 \%$ of AS patients are HLA-B27 positive; however, only $1-5 \%$ of HLA-B27 carriers develop AS (Calin et al. 1983), and family and twin studies suggest that HLA-B27 contributes to $<50 \%$ of the genetic risk of AS (Brown et al. 1997; Rubin et al. 1994). Consistently, genes other than HLA-B27 have also been implicated in AS, including $I L 1 A / B$ (Maksymowych et al. 2006), ILIRN (van der Paardt et al. 2002), IL10 (Goedecke et al. 2003), CYP1A1 (Yen et al. 2003), CYP2D6 (Beyeler et al. 1996), ANKH (Tsui et al. 2003), and NPPS (Mori et al. 2003). However, the significance of these genes remains to be elucidated. Most of these associations are not replicated in other populations, in particular those of different ethnicities.

AS patients show marked ectopic ossification in the spine, occasionally resulting in so-called "bamboo spine" (Calin 1998). Therefore, genes involved in ectopic ossification and/or calcification are good candidates for the AS susceptibility gene. Indeed, the polymorphisms of $A N K H$, which encodes the transporter of inorganic pyrophosphate (PPi), a major inhibitor of calcification, show association with AS (Tsui et al. 2003). In this study, we conducted an association study to identify novel susceptibility alleles for AS and to examine previously reported association in Japanese and Taiwanese populations. We report promising evidence for the association between $M S X 2$ polymorphisms and AS and replication of the association between $A N K H$ polymorphism and AS.

\section{Materials and methods}

\section{Study subjects}

In the Japanese study, a 278 individuals with sporadic AS (255 males and 23 females) were recruited though four medical facilities. In the Taiwanese study, 219 affected individuals (156 males and 63 females) were recruited though two facilities. We obtained written informed consent from each patient. The study protocols were approved by the ethical committees at each institution. AS was defined by the modified New York diagnostic criteria (van der Linden et al. 1984). The mean age of Japanese and Taiwanese AS patients was 41.2 (16-78) years and 36.0 (9-89) years, respectively. Two hundred and thirty-three of 278 Japanese patients and 213 of 219 Taiwanese patients were HLA-B27 positive.

In the Japanese study, we used up to 896 subjects (508 males and 388 females) from the general population as controls in analyses of 31 single nucleotide polymorphisms (SNPs) for which genotype data were available from the
Japanese Single Nucleotide Polymorphism (JSNP) database (Haga et al. 2002). The mean age of control subjects was 48.5 (3-88) years. We genotyped 376 controls (205 males and 171 females) from the general population for analyses of the 14 SNPs for which genotype data were not available in the JSNP. The mean age of this control group was 42.1 (14-92) years. In the Taiwanese study, we used 185 controls ( 80 males and 105 females) from the general population. The mean age of the Taiwanese control group was $46.3(20-78)$ years.

Selection of candidate genes and marker SNPs

Fifteen candidate genes were selected (Table 1) according to the following criteria: (1) genes previously reported to be associated with AS and (2) genes known to be involved in ectopic ossification and/or calcification. We selected SNPs in the candidate genes that had minor allele frequencies $>10 \%$ from JSNP (Haga et al. 2002) and the National Center for Biotechnology Information (NCBI) dbSNP database (http://www.ncbi.nlm.nih.gov/).

\section{Genotyping}

Genomic DNA was extracted from blood as standard procedure. SNP genotyping was performed using the Invader assay and the TaqMan assay as described previously (Ohnishi et al. 2001; Suzuki et al. 2003).

\section{Statistical analysis}

The differences in allelic distribution between cases and controls and Hardy-Weinberg equilibrium in controls were assessed by the $\chi^{2}$ test. We performed the first screen using 170 Japanese AS patients and up to 896 controls. A $P$ value $<0.05$ was considered statistically significant in any of the following models: genotypic, dominant, recessive, and allelic. In the second screen, 108 additional Japanese patients were genotyped and assessed by the $\chi^{2}$ test with Bonferroni's correction for multiple testing. Pairwise linkage disequilibrium (LD) was estimated as described previously (Kizawa et al. 2005). Haplotype frequencies were estimated by the expectation-maximization algorithm and Arlequin softwave. We checked the replication of the association of the most significant SNP by genotyping 219 Taiwanese AS patients and 185 controls.

\section{Results}

We first screened 45 SNPs from 15 candidate genes (Table 1). Eight SNPs in six genes that cleared the cutoff point of $P<0.05$ were subjected to the second screen. 
In the combined results of the first and second screens, four SNPs from distinct genes showed the nominal $P$ values $<0.05$ (Table 2). An intronic SNP in MSX2 (IVS1 + 996G $>$ A) showed the most significant association $(P=0.0030)$.

To examine LD around the MSX2 region, we constructed a pairwise LD block by genotyping six SNPs around MSX2 from the NCBI dbSNP for 376 controls. We found that $M S X 2$ was contained completely within a single LD block (Fig. 1). The level of association of promoter $-3,742 \mathrm{C}>\mathrm{T}$ was equivalent to that of IVS1 $+996 \mathrm{G}>\mathrm{A}$ (Table 3). The haplotypes were assessed by four SNPs within the MSX2 region. The $P$ values of haplotype association were less significant than those of respective SNPs (data not shown), indicating that the presence of a hidden SNP that shows more significant association than IVS1 + 996G $>$ A is unlikely. These associations were not affected by the stratification of AS patients according to HLA-B27 and gender status (data not shown). The significance disappeared after Bonferroni's correction for multiple testing of 45 SNPs

The association between IVS1 $+996 \mathrm{G}>\mathrm{A}$ and AS was not replicated in a Taiwanese population (Table 4). However, allelic frequency distribution of IVS $+996 \mathrm{G}>\mathrm{A}$ in the Taiwanese population showed the same trend observed in the Japanese population, and the odds ratio (OR) in the Taiwanese population also exceeded 1 , as in the Japanese population. Power calculations indicated that the Japanese study sample had an $85 \%$ power to detect association of IVS1 + 996G > A with an OR of 1.51 and a 0.05 significance level, whereas Taiwanese study sample had only an $67 \%$ power under the same condition as the Japanese study.

Among SNPs located in genes previously reported to have association with AS, only one synonymous SNP, c.963T $>\mathrm{G}$ in $A N K H$, showed a marginal association $(P=0.045)($ Table 2$)$.
Table 1 Ankylosing spondylitis (AS) candidate genes examined in this study

Group 1: genes previously reported to be associated with AS, Group 2: genes known to be involved in ectopic ossification and/or calcification

Table 2 Combined results of the first and second screens in a Japanese population

Genotype: number of homozygotes for the minor allele/heterozygotes/ homozygotes for the major allele

dbSNP Database for Single Nucelotide Polymorphisms

a The best result according to the indicated model

\begin{tabular}{lllll}
\hline Group & Gene symbol & Gene name & Locus & Accession no. \\
\hline 1 & IL1RN & Interleukin 1 receptor antagonist & 2q & NM_000577 \\
& IL10 & Interleukin 10 & $1 \mathrm{q}$ & NM_000572 \\
ANKH & Ankylosis, progressive homolog (mouse) & $5 \mathrm{p}$ & NM_054027 \\
NPPS & Nucleotide pyrophosphatase & $6 \mathrm{q}$ & NM_006208 \\
CYP2D6 & Cytochrome P450, family 2, subfamily D, polypeptide 6 & 22q & NM_000106 \\
NOD2 & Nucleotide-binding oligomerization domain containing 2 & 16q & NM_022162 \\
HSPA1L & Heat shock 70 kDa protein 1-like & $6 \mathrm{p}$ & NM_005527 \\
BMP4 & Bone morphogenetic protein 4 & $14 \mathrm{q}$ & NM_001202 \\
CSPG2 & Chondroitin sulfate proteoglycan 2 (versican) & $5 \mathrm{q}$ & NM_004385 \\
CST3 & Cystatin C (amyloid angiopathy and cerebral hemorrhage) & 20p & NM_000099 \\
EDN1 & Endothelin 1 & $6 \mathrm{p}$ & NM_001955 \\
MSX2 & MSH homeobox homolog 2 (drosophila) & 5q & NM_002449 \\
SNAI1 & Snail homolog 1 (drosophila) & 20q & NM_005985 \\
SNAI2 & Snail homolog 2 (drosophila) & 8q & NM_003068 \\
ZNF145 & Zinc finger protein 145 & 11q & NM_006006 \\
\hline
\end{tabular}

\begin{tabular}{|c|c|c|c|c|c|c|}
\hline \multirow[t]{2}{*}{ Gene symbol } & \multirow[t]{2}{*}{ Sequence variation } & \multirow[t]{2}{*}{ dbSNP ID } & \multicolumn{2}{|l|}{ Genotype } & \multicolumn{2}{|l|}{$\chi^{2}$ test } \\
\hline & & & Case & Control & $P$ value $^{\mathrm{a}}$ & Model \\
\hline$M S X 2$ & IVS1 $+996 \mathrm{G}>\mathrm{A}$ & rs4868442 & $7 / 86 / 185$ & $21 / 144 / 209$ & 0.0030 & Allele \\
\hline ANKH & c. $963 \mathrm{~T}>\mathrm{C}$ & rs2288474 & $13 / 81 / 183$ & $17 / 209 / 512$ & 0.0452 & $\mathrm{CC}$ versus others \\
\hline CSPG2 & IVS5 + 2599T $>$ A & rs2292012 & $47 / 133 / 97$ & $183 / 396 / 253$ & 0.0481 & Allele \\
\hline EDN1 & IVS4-208C > T & rs1630736 & $59 / 147 / 69$ & $72 / 183 / 121$ & 0.0493 & $\mathrm{CC}$ versus others \\
\hline ILIO & $\mathrm{IVS} 2+56 \mathrm{~A}>\mathrm{G}$ & rs1518111 & $17 / 125 / 136$ & $72 / 333 / 341$ & 0.0740 & AA versus others \\
\hline CSPG2 & IVS1-463A > G & rs884571 & 28/103/146 & $96 / 351 / 392$ & 0.0839 & GG versus others \\
\hline ZNF145 & IVS3-5770A > G & rs2073848 & $32 / 92 / 153$ & $67 / 296 / 379$ & 0.1135 & Genotype \\
\hline CSPG2 & IVS1-319T >C & rs1867667 & $55 / 130 / 92$ & $194 / 399 / 244$ & 0.1308 & Allele \\
\hline
\end{tabular}




\section{Discussion}

We found that MSX2 polymorphisms are associated with AS in Japanese but not in Taiwanese. Because the power to detect the association of MSX2 polymorphisms in Taiwanese is smaller than that in Japanese, we might have missed a causal variant in Taiwanese. Alternatively, the discrepant results may arise from population and/or environmental differences. In either case, more studies including those in different ethnic groups are needed to confirm the significance of the association between MSX2 polymorphisms and AS.

MSX2 is a transcription factor with a homeobox domain and involved in bone development and ectopic calcification. However, its roles in these processes are still controversial. Msx2-deficient mice shows reduced bone formation, decreased osteoblasts, impaired chondrogenesis, and abnormal calvarial development (Satokata et al. 2000). Transgenic mice overexpressing Msx2 shows enhanced proliferation of calvarial cells (Liu et al. 1999). A loss-offunction mutation of $M S X 2$ in humans, which reduces

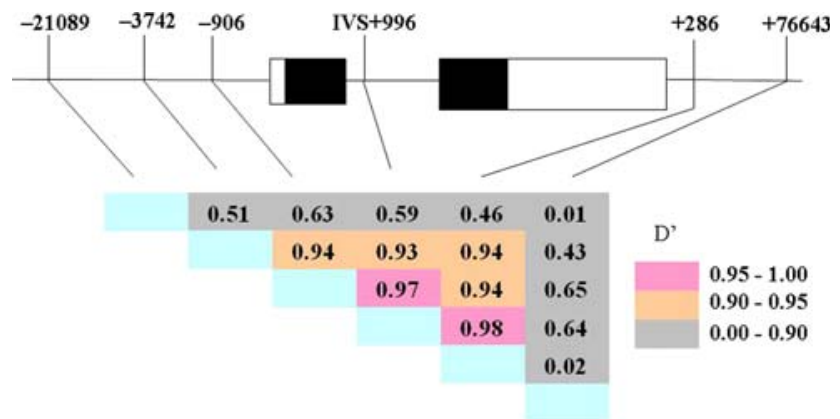

Fig. 1 The linkage disequilibrium (LD) block around MSX2. Top panel: genomic structure and sequence variations of $M S X 2$. Exons are denoted by rectangles, and coding regions are filled. Nucleotide A of the translation initiation codon (ATG) is denoted as +1 to show the position in promoter. First nucleotide of $3^{\prime}$-flanking region is denoted as +1 to show the position in $3^{\prime}$-flanking region. Bottom panel: LD structure containing $M S X 2$. LD was evaluated using $\mathrm{D}^{\prime}$ statistical analysis
DNA binding activity, causes defects in skull ossification (Wilkie et al. 2000), whereas a gain-of-function mutation of MSX2 results in an autosomal dominant disorder, Boston-type craniosynostosis (Jabs et al. 1993; Ma et al. 1996). Msx2 transgenic mice under the control of the cytomegalovirus (CMV) promoter exhibits marked cardiovascular calcification because the Msx2-expressing myofibroblasts produce an osteogenic milieu (Shao et al. 2005). These findings suggest a positive role for MSX2 in bone development and ectopic calcification. In contrast, other studies have indicated that MSX2 negatively regulates bone development and ectopic calcification. MSX2 abrogates the promoter activity of osteoblast marker genes such as osteocalcin (Newberry et al. 1997). MSX2 inhibits the transcriptional activity of RUNX2, a master regulator of osteoblast differentiation (Shirakabe et al. 2001). MSX2 plays a role in preventing ligaments and tendons from calcification (Yoshizawa et al. 2004). The roles of MSX2 may vary depending on cell type and/or cell differentiation stage.

The ank (progress ankylosis) is a natural mutant mouse that has a mutation in the gene encoding PPi transporter in the plasma membrane. The ank exhibits phenotypes similar to AS. The mutation leads to low extracellular PPi (Ho et al. 2000). Because PPi is a major inhibitor of ossification and calcification, reduced extracellular PPi levels cause ectopic ossification and/or calcification, leading to ankylosis (Ikegawa 2006). Decreased serum nucleotide pyrophosphatase (NPPS), an enzyme that produces PPi from nucleotide pyrophosphate (Okawa et al. 1998), was reported in AS patients (Mori et al. 2003). A previous study showed that the polymorphisms of $A N K H$ (human homolog of ank) are associated with susceptibility to AS in American Caucasians (Tsui et al. 2003), whereas a large British study found no such association (Timms et al. 2003). In this study, a synonymous $\mathrm{SNP}$, c.963A $>\mathrm{G}$ in $A N K H$, showed a marginal association. The effect of the $A N K H$ polymorphisms on AS susceptibility may be small and/or intrinsically different, leading to discrepant results between populations.

Table 3 Association of single nucleotide polymorphisms (SNPs) in MSX2 with alkankylosing spondylitis (AS)

\begin{tabular}{|c|c|c|c|c|c|c|c|c|}
\hline \multirow[t]{2}{*}{ Sequence variation } & \multirow[t]{2}{*}{ dbSNP ID } & \multicolumn{2}{|l|}{ Genotype } & \multicolumn{2}{|c|}{ Allelic frequency } & \multicolumn{3}{|l|}{$\chi^{2}$ test } \\
\hline & & Case & Control & Case & Control & $P$ value $^{\mathrm{a}}$ & Model & OR $(95 \% \mathrm{CI})$ \\
\hline Promoter $-3742 \mathrm{C}>\mathrm{T}$ & rs6884071 & $9 / 90 / 178$ & $25 / 149 / 201$ & 0.195 & 0.265 & 0.0031 & Allele & $1.49(1.14-1.94)$ \\
\hline Promoter $-906 \mathrm{C}>\mathrm{A}$ & rs7447819 & $9 / 79 / 190$ & $17 / 130 / 227$ & 0.174 & 0.219 & 0.0442 & $\mathrm{CC}$ versus others & $1.40(1.01-1.94)$ \\
\hline $\mathrm{IVS} 1+996 \mathrm{G}>\mathrm{A}$ & rs4868442 & $7 / 86 / 185$ & $21 / 144 / 209$ & 0.180 & 0.249 & 0.0030 & Allele & $1.51(1.15-1.98)$ \\
\hline 3'flanking $+286 \mathrm{C}>\mathrm{T}$ & rs4647949 & $27 / 121 / 130$ & $52 / 174 / 150$ & 0.315 & 0.370 & 0.039 & Allele & $1.28(1.01-1.61)$ \\
\hline
\end{tabular}

Genotype: number of homozygotes for the minor allele/heterozygotes/homozygotes for the major allele $d b S N P$ Database of Single Nucleotide Polymorphisms, $O R$ odds ratio, $C I$ confidence interval

a The best results according to the indicated model 
Table 4 Association of MSX2 IVS1 + 996G > A in Taiwanese ankylosing spondylitis (AS) patients

\begin{tabular}{|c|c|c|c|c|c|c|}
\hline \multicolumn{2}{|l|}{ Genotype } & \multicolumn{2}{|c|}{$\begin{array}{l}\text { Allelic } \\
\text { frequency }\end{array}$} & \multicolumn{3}{|c|}{$\chi^{2}$ test } \\
\hline Case & Control & Case & Control & $\begin{array}{l}P \\
\text { value }\end{array}$ & Model & $\begin{array}{l}\text { OR } \\
(95 \% \mathrm{CI})\end{array}$ \\
\hline $13 / 78 / 128$ & $17 / 64 / 104$ & 0.237 & 0.265 & 0.370 & Allele & $\begin{array}{l}1.16 \\
\quad(0.84-1.59)\end{array}$ \\
\hline
\end{tabular}

Genotype: number of homozygotes for the minor allele/heterozygotes/homozygotes for the major allele

$O R$ odds ratio, $C I$ confidence interval

This study provides promising evidence for the association between MSX2 polymorphisms and AS and the replication of the association between ANKH polymorphisms and AS in the Japanese population.

Acknowledgments We thank individuals for participating the study. We also thank Dr. N. Tsuchiya for help in collecting samples and critical advice, and Dr. S. Tominaga, Mr. Yung-Feng Lin, and Ms. Ting-Chun Liu for technical assistance.

\section{References}

Beyeler C, Armstrong M, Bird HA, Idle JR, Daly AK (1996) Relationship between genotype for the cytochrome P450 CYP2D6 and susceptibility to ankylosing spondylitis and rheumatoid arthritis. Ann Rheum Dis 55:66-68

Brewerton DA, Hart FD, Nicholls A, Caffrey M, James DC, Sturrock RD (1973) Ankylosing spondylitis and HL-A 27. Lancet 1:904907

Brown MA, Kennedy LG, MacGregor AJ, Darke C, Duncan E, Shatford JL, Taylor A, Calin A, Wordsworth P (1997) Susceptibility to ankylosing spondylitis in twins: the role of genes, HLA, and the environment. Arthritis Rheum 40:1823-1828

Brown MA, Wordsworth BP, Reveille JD (2002) Genetic of ankylosing spondylitis. Clin Exp Rheumatol 20:S43-S49

Calin A (1998) Anklosing spondylitis. In: Maddison PJ, Isenberg DA, Woo P, Glass DN (eds) Oxford textbook of rheumatology, vol 2. Oxford University Press, Oxford, pp 1058-1070

Calin A, Marder A, Becks E, Burns T (1983) Genetics differences between B27 positive patients with ankylosing spondylitis and B27 positive healthy controls. Arthritis Rheum 26:1460-1464

Goedecke V, Crane AM, Jaakkola E, Kaluza W, Laiho K, Weeks DE, Wilson J, Kauppi M, Kaarela K, Tuomilehto J, Wordsworth BP, Brown MA (2003) Interleukin 10 polymorphisms in ankylosing spondylitis. Genes Immun 4:74-76

Haga H, Yamada R, Ohnishi Y, Nakamura Y, Tanaka T (2002) Genebased SNP discovery as part of the Japanese Millennium Genome Project: identification of 190,562 genetic variations in the human genome. Single-nucleotide polymorphism. J Hum Genet 47:605-610

Ho AM, Johnson MD, Kingsley DM (2000) Role of the mouse ank gene in control of tissue calcification and arthritis. Science 289:265-270

Ikegawa S (2006) Tiptoe walking (ttw) mouse. In: Yonenobu K, Nakamura K, Toyama Y (eds) OPLL (ossification of the posterior longitudinal ligament), 2nd edn. Springer, Tokyo, pp $71-75$
Jabs EW, Müller U, Li X, Ma L, Luo W, Haworth IS, Klisak I, Sparkes R, Warman ML, Mulliken JB, Snead ML, Maxson R (1993) A mutation in the homeodomain of the human MSX2 gene in a family affected with autosomal dominant craniosynostosis. Cell 75:443-450

Kizawa H, Kou I, Iida A, Sudo A, Miyamoto Y, Fukuda A, Mabuchi A, Kotani A, Kawakami A, Yamamoto S, Uchida A, Nakamura K, Notoya K, Nakamura Y, Ikegawa S (2005) An aspartic acid repeat polymorphism in asporin inhibits chondrogenesis and increases susceptibility to osteoarthritis. Nat Genet 37:138-144

Liu YH, Tang Z, Kundu RK, Wu L, Luo W, Zhu D, Sangiorgi F, Snead ML, Maxson RE (1999) Msx2 gene dosage influences the number of proliferative osteogenic cells in growth centers of the developing murine skull: a possible mechanism for MSX2mediated craniosynostosis in humans. Dev Biol 205:260-274

Ma L, Golden S, Wu L, Maxson R (1996) The molecular basis of Boston-type craniosynoptosis: the Pro148His mutation in the Nterminal arm of the MSX2 homeodomain stabilizes DNA binding without altering nucleotide sequence preferences. Hum Mol Genet 5:1915-1920

Maksymowych WP, Rahman P, Reeve JP, Gladman DD, Peddle L, Inman RD (2006) Association of the IL1 gene cluster with susceptibility to ankylosing spondylitis: an analysis of three Canadian populations. Arthritis Rheum 54:974-985

Mori K, Chano T, Ikeda T, Ikegawa S, Matsusue Y, Okabe H, Saeki Y (2003) Decrease in serum nucleotide pyrophosphatase activity in ankylosing spondylitis. Rheumatology 42:62-65

Newberry EP, Boudreaux JM, Towler DA (1997) Stimulus-selective inhibition of rat osteocalcin promoter induction and proteinDNA interactions by the homeodomain repressor Msx2. J Biol Chem 272:29607-29613

Ohnishi Y, Tanaka T, Ozaki K, Yamada R, Suzuki H, Nakamura Y (2001) A high-throughput SNP typing system for genome-wide association studies. J Hum Genet 46:471-477

Okawa A, Nakamura I, S Goto, Moriya H, Nakamura Y, Ikegawa S (1998) Mutation in Npps in a mouse model of ossification of the posterior longitudinal ligament of the spine. Nat Genet 19:271273

Rubin LA, Amos CI, Wade JA, MartinJR, Bale SJ, Little AH, Gladman DD, Bonney GE, Rubenstein JD, Siminovitch KA (1994) Investigating the genetic basis for ankylosing spondylitis: linkage studies with the major histocompatibility complex region. Arthritis Rheum 37:1212-1220

Satokata I, Ma L, Ohshima H, Bei M, Woo I, Nishizawa K, Maeda T, Takano Y, Uchiyama M, Heaney S, Peters H, Tang Z, Maxson R, Maas R (2000) Msx2 deficiency in mice causes pleiotropic defects in bone growth and ectodermal organ formation. Nat Genet 24:391-395

Shao JS, Cheng SL, Pingsterhaus JM, Charlton-Kachigian N, Loewy AP, Towler DA (2005) Msx2 promotes cardiovascular calcification by activating paracrine Wnt signals. J Clin Invest 115:1210-1220

Shirakabe K, Terasawa K, Miyama K, Shibuya H, Nishida E (2001) Regulation of the transcription factor Runx 2 by two homeobox proteins, Msx2 and Dlx5. Genes Cells 6:851-856

Suzuki A, Yamada R, Chang X, Tokuhiro S, Sawada T, Suzuki M, Nagasaki M, Nakayama-Hamada M, Kawaida R, Ono $M$, Ohtsuki M, Furukawa H, Yoshino S, Yukioka M, Tohma S, Matsubara T, Wakitani S, Teshima R, Nishioka Y, Sekine A, Iida A, Takahashi A, Tsunoda T, Nakamura Y, Yamamoto K (2003) Functional haplotypes of PADI4, encoding citrullinating enzyme peptidylarginine deiminase 4 , are associated with rheumatoid arthritis. Nat Genet 34:395-402

Timms AE, Zhang Y, Bradbury L, Wordsworth BP, Brown MA (2003) Investigation of the role of $A N K H$ in ankylosing spondylitis. Arthritis Rheum 48:2898-2902 
Tsui FWL, Tsui HW, Cheng EY, Stone M, Payne U, Reveille JD, Shulman MJ, Paterson AD, Inman RD (2003) Novel genetic markers in the $5^{\prime}$-flanking region of $A N K H$ are associated with ankylosing spondylitis. Arthritis Rheum 48:791-797

van der Linden S, Valkenburg HA, Cats A (1984) Evaluation of diagnostic criteria for ankylosing spondylitis. A proposal for modification of the New York criteria. Arthritis Rheum 27:361368

van der Paardt M, Crusius JB, Garcia-Gonzalez MA, Baudoin P, Kostense PJ, Alizadeh BZ, Dijkmans BA, Pena AS, van der Horst-Bruinsma IE (2002) Interleukin-1beta and interleukin-1 receptor antagonist gene polymorphisms in ankylosing spondylitis. Rheumatology 41:1419-1423
Wilkie AOM, Tang Z, Elanko N, Walsh S, Twigg SRF, Hurst JA, Wall SA, Chrzanowska KH, Maxson RE (2000) Functional haploinsufficiency of the human homeobox gene MSX2 causes defects in skull ossification. Nat Genet 24:387-390

Yen JH, Tsai WC, Chen CJ, Lin CH, Ou TT, Hu CJ, Liu HW (2003) Cytochrome P450 1A1 and manganese superoxide dismutase genes polymorphisms in ankylosing spondylitis. Immunol Lett $88: 113-116$

Yoshizawa T, Takizawa F, Iizawa F, Ishibashi O, Kawashima $\mathrm{H}$, Matsuda A, Endo N, Kawashima H (2004) Homeobox protein Msx2 Acts as a molecular defense mechanism for preventing ossification in ligament fibroblasts. Mol Cell Biol 24:3460-3472 